Annals of Surgery

DOI: $10.1097 /$ SLA.0000000000004584

\title{
Laparoscopic Colorectal Surgery Outcomes Improved After National Training Program (LAPCO) for Specialists in England
}

George B Hanna ${ }^{1} \mathrm{PhD}$, Hugh Mackenzie ${ }^{1} \mathrm{PhD}$, Danilo Miskovic ${ }^{1,2} \mathrm{PhD}$, Melody $\mathrm{Ni}^{1} \mathrm{PhD}$, Susannah Wyles ${ }^{1} \mathrm{PhD}$, Paul Aylin ${ }^{3} \mathrm{PhD}$, Amjad Parvaiz ${ }^{4}$ FRCS, Tom Cecil ${ }^{5} \mathrm{MD}$, Andrew Gudgeon $^{6}$ FRCS, John Griffith ${ }^{7}$ FRCS, Jonathan M Robinson ${ }^{7}$ MD, Chelidah Selvasekar ${ }^{8}$ MD, Tim Rockall ${ }^{9} \mathrm{MD}$, Austin Acheson ${ }^{10} \mathrm{MD}$, Charles Maxwell-Armstrong ${ }^{10}$, John T Jenkins ${ }^{1,2}$ FRCS, Alan Horgan ${ }^{11}$ MD, Chris Cunningham ${ }^{12}$ MD, Ian Lindsay ${ }^{12}$ FRACS, Tan Arulampalam ${ }^{13} \mathrm{MD}$, Roger W Motson ${ }^{13} \mathrm{MD}$, Nader K Francis ${ }^{14} \mathrm{PhD}$, Robin H Kennedy ${ }^{1,2}$ FRCS, Mark G Coleman ${ }^{15} \mathrm{MD}$ on behalf of Lapco program

1. Department of Surgery and Cancer, Imperial College London

2. Department of Colorectal Surgery, St Mark's Hospital, North West London NHS Trust, London

3. School of Public Health, Imperial College London

4. Department of Surgery, Pool Hospital NHS Foundation Trust, Poole

5. Department of Colorectal Surgery, Hampshire Hospitals NHS Foundation Trust, Basingstoke

6. Department of Colorectal Surgery, Frimley Health NHS Foundation Trust, London

7. Department of Colorectal Surgery, Bradford Teaching Hospitals NHS Foundation Trust, Bradford

8. Department of Colorectal Surgery, Christie NHS Foundation Trust, Manchester

9. Department of Colorectal Surgery, Royal Surrey County Hospital NHS Trust, Guildford

10. Department of Gastrointestinal Surgery, Nottingham University Hospitals NHS Trust, Nottingham

11. Department of Colorectal Surgery, Freeman Hospital, Newcastle upon Tyne Hospitals NHS Trust, Newcastle

12. Department of Colorectal Surgery, Churchill Hospital, Oxford University Hospitals NHS Trust, Oxford

13. Department of Colorectal Surgery, Colchester Hospital, East Suffolk and North Essex NHS Foundation Trust, Colchester

14. Department of General Surgery, Yeovil District Hospital NHS Foundation Trust, Yeovil

15. Department of Colorectal Surgery, Plymouth Hospitals NHS Trust, Plymouth

Copyright @ 2020 Wolters Kluwer Health, Inc. Unauthorized reproduction of this article is prohibited. 


\section{Corresponding author:}

Professor George B Hanna PhD FRCS

Head of Department of Surgery and Cancer

Department of Surgery and Cancer

Imperial College London

10th Floor, QEQM, St Mary's Hospital

Praed St London W2 1NY

United Kingdom

Tel: (+) 442033122124

Fax: (+) 442033126309

E Mail: g.hanna@imperial.ac.uk

Word count: 2973

Table: 1

Figures: 4

\section{Funding}

Department of Health, England

\section{Conflict of interest}

We declare that we have no conflict of interest.

Running head: Clinical outcomes after Lapco program (38/40 characters) 


\section{MINI ABSTRACT (49/50 words)}

The National Training Program for Laparoscopic Colorectal Surgery (Lapco) for specialist colorectal surgeons was safely realized in England. After completion of training, Lapco delegates performed more laparoscopic cases with a lower re-intervention, 30-day and 90-day mortality rate compared non-Lapco surgeons. Competency-based assessment tools during training predicted clinical performance post-Lapco.

\section{ABSTRACT \\ OBJECTIVE}

To examine the impact of The National Training Programme for Laparoscopic Colorectal Surgery (Lapco) on the rate of laparoscopic surgery and clinical outcomes of cases performed by Lapco surgeons after completion of training.

\section{SUMMERY BACKGROUND DATA}

Lapco provided competency-based supervised clinical training for specialist colorectal surgeons in England.

\section{METHODS}

We compared the rate of laparoscopic surgery, mortality and morbidity for colorectal cancer resections by Lapco delegates and non-Lapco surgeons in 3-year periods preceding and following Lapco using difference in differences analysis. The changes in the rate of postLapco laparoscopic surgery with the Lapco sign-off competency assessment and in-training global assessment scores were examined using risk-adjusted cumulative sum to determine their predictive clinical validity with predefined competent scores of 3 and 5 respectively.

\section{RESULTS}

108 Lapco delegates performed 4586 elective colorectal resections pre-Lapco and 5115 postLapco while non-Lapco surgeons performed 72930 matched cases. Lapco delegates had a $37.8 \%$ increase in laparoscopic surgery which was greater than non-Lapco surgeons by $20.9 \%$ (95\% CI, 18.5 to $23.3, \mathrm{p}<0.001$ ) with a relative decrease in 30 -day mortality by $-1.6 \%$ $(95 \% \mathrm{CI},-3.4$ to $-0.2, \mathrm{p}=0.039)$ and 90 -day mortality by $-2.3 \%(95 \% \mathrm{CI},-4.3$ to -0.4 , $\mathrm{p}=0.018$ ). The change point of risk-adjusted cumulative sum was 3.12 for competency assessment tool and 4.74 for global assessment score whereas laparoscopic rate increased from $44 \%$ to $66 \%$ and $40 \%$ to $56 \%$ respectively.

\section{CONCLUSIONS}

Lapco increased the rate of laparoscopic colorectal cancer surgery and reduced mortality and morbidity in England. In-training competency assessment tools predicted clinical performance after training. 


\section{BACKGROUND}

Specialist doctors rely on short courses, proctorship schemes and visits to centers of excellence to acquire the necessary skills for new procedures. The experience gained during subsequent independent practice is reported as a 'learning or proficiency-gain curve' to describe the change in complication rates with the increase in procedural experience. ${ }^{1,2}$ The proficiency-gain curve for the introduction of laparoscopic surgery for gastrointestinal cancer in England was associated with increased mortality and major morbidity ${ }^{2}$.

Randomized controlled trials confirmed improved short-term outcomes of laparoscopic colorectal surgery compared to the open approach. ${ }^{3-6}$ In response to this evidence, the UK National Institute of Health and Care Excellence issued a technology appraisal in 2006 stating that all suitable patients with colorectal cancer should be offered the option of laparoscopic surgery when undergoing resections of the colon or rectum. ${ }^{7}$ However, after publishing this guideline it was recognized that only a minority of surgeons in the UK would be able to offer laparoscopic colorectal surgery. Therefore, the guidelines were waived and the Department of Health of England created the National Training Program for Laparoscopic Colorectal Surgery (Lapco) to provide a safe and high-quality supervised clinical training for specialist colorectal surgeons ('consultants') in England.

Lapco had several unique characteristics. It was the first national initiative to offer specialists skills training in an emerging surgical technology by one-to-one expert supervision in the operating theatre. As an integral part of Lapco, objective training assessment tools were developed and employed ${ }^{8-10}$ to monitor training progression and to sign off delegates to progress to independent laparoscopic colorectal practice based on surgical competency rather than time-served or the number of training cases. In addition, training quality was standardized, benchmarked and demonstrably improved through the Lapco Training-theTrainer curriculum ${ }^{11}$. The quality of each training episode was monitored using a specifically-developed assessment tool ${ }^{12}$.

The primary aim of this study was to examine the impact of Lapco on the rate of laparoscopic surgery and clinical outcomes of cases performed by Lapco surgeons after completion of training. The secondary aim is to assess the predictive clinical validity of training assessment tools employed during and at completion of training.

\section{METHODS}

\section{Design of Lapco}

The Lapco program commenced in 2006 and concluded in 2013. Only colorectal consultant surgeons ('delegates') were eligible to apply for training in 11 Lapco national centers. Each delegate was allocated to a nearby training center to have one-to-one laparoscopic training by experts. Lapco focused on training laparoscopic right and left sided colonic resections.

Training did not include single port or robotic surgery. The exact laparoscopic technique was left to discretion of the expert trainer, although techniques remained similar throughout the program and standardized through Lapco Training-the-Trainer curriculum. Lapco centers also offered preclinical optional laboratory training based on delegates' needs. By 2013, national 
data were available that demonstrated significant increase in the utilization of laparoscopic colorectal surgery in most hospitals in England and therefore, the program came to an end. The structure of Lapco is described in the Supplement, http://links.lww.com/SLA/C719.

\section{Safety and quality of training during Lapco}

Clinical outcomes during Lapco were examined to determine the safety and proficiency-gain curves of supervised training.

Monitoring training progression. The trainer and delegate separately assessed the level of trainer input required to complete each procedure (divided into thirteen distinct tasks) using the Global Assessment Scale (GAS) on a 1-6 scale with 5 representing competent performance by the delegate. ${ }^{8}$ Consecutive scores delineated proficiency-gain curves that were accessed online to monitor training progression. Submission of the GAS was mandatory.

Competency assessment to sign off delegates to independent practice. Both delegate and trainer initiated the sign-off process once there was agreement that the delegate had reached a level suitable for independent practice. Delegates submitted recordings of two independently performed operative procedures, to the educational center at Imperial College where cases were decoded and sent to two Lapco assessors, who were Lapco trainers not involved in the delegate's training and blind to his/her identity. They assessed four skill areas in four components of each procedure using Competency Assessment Tool (CAT) ${ }^{9}$ on a 1-4 scale with 3 representing competent performance. Although the sign-off competency assessment was strongly encouraged, it was not mandatory by Lapco because delegates performance post-Lapco was governed by their employing hospitals.

Assessment of training quality. Each delegate quantified training quality for each procedure in terms of structure, delivery and trainer's attributes on 1-5 scale using the Structured Training Trainer Assessment Report (mini-STTAR form) ${ }^{12}$ once developed. At the conclusion of Lapco, delegates and trainers assessed training structure using an online questionnaire (Supplement, http://links.lww.com/SLA/C719).

The training metrics of a Lapco delegate thus comprised of CAT score, delegate and trainer GAS scores (average score of the final three GAS forms), training volume (number of Lapco cases performed by the delegate) and training frequency (average number of Lapco cases per month).

\section{Clinical outcomes post-Lapco}

We performed a case-control study to retrospectively compare clinical outcomes of laparoscopic cases performed by Lapco-delegates versus those by non-Lapco surgeons. We examined all colorectal resections performed by Lapco delegates $(n=144)$ in the three years following their last Lapco training case (post-Lapco). The comparative period included all colorectal resections by Lapco delegates in the three-years preceding their first Lapco training case (pre-Lapco). Delegates who performed less than 5 Lapco training cases $(n=36)$, the lowest quartile of training volume, were excluded from this analysis. These delegates did not complete their training when Lapco came to an end or for practical reasons related to job planning or personal circumstances. All other Lapco delegates were included in the analysis 
whether they passed the sign-off process or not. Data were extracted from Hospital Episode Statistics (HES), which is an administrative database that records all admissions to NHS hospitals throughout England. Data was entered in HES database by independent encoders (administrators) and managed independently (available in the Supplement, http://links.lww.com/SLA/C719). Lapco delegates and trainers were identified by the General Medical Council number and patients were tracked throughout the dataset using a unique anonymized HES identifier. Date of death was obtained from the Office for National Statistics. Exclusion criteria included non-cancer diagnosis, emergency resections, patients aged less than 17 years and complex resections (total colectomy, subtotal colectomy, transverse colectomy and abdomino-perineal resections).

\section{Outcome measures}

The primary outcome was the rate of laparoscopic surgery. Other outcomes included 30-day, 90-day and one-year mortality, re-intervention (any unplanned return to the operating theatre, radiologically guided or interventional endoscopic procedure within 30 days of initial surgery), length of hospital stay, re-admission (emergency admission within 30 days of discharge), conversion and medical complication (any new medical diagnoses made within 30 days of the operation date, either during the initial admission or subsequent re-admission).

\section{Statistical analysis}

We compared the rate of laparoscopic colorectal cancer surgery and clinical outcomes for cases performed by the Lapco delegates pre- and post-Lapco. Univariate comparisons were carried out; Chi-squared for categorical variables, Mann-Whitney U for length of hospitalstay and t-test for continuous variables. We accounted for confounding demographics by creating pre- and post-Lapco generalized linear mixed effects models for the laparoscopic cases carried out by all Lapco delegates (eTable 1 in the Supplement, http://links.lww.com/SLA/C719). The dependent variables were the clinical outcomes of laparoscopic cases. The independent variables were Charlson co-morbidity index $(<3, \geq 3)$, age category $(<50,50-65,66-75,76-85,>85)$, gender, resection type (right colectomy, extended right colectomy, left colectomy, sigmoid colectomy and anterior resection) and Carstairs index of deprivation (quintile) with fixed effects and specialists with random effects. The same case mix variables were used to derive propensity scores for case matching and for risk adjustment in CUSUM analyses (see below).

We performed difference-in-differences analyses to eliminate non-training factors as the cause for the change in clinical outcomes over time. The differences in the pre- versus postLapco outcomes from cases performed by the Lapco delegates were compared against the differences in the same outcomes over the same time periods from two control cohorts (see equation in the Supplement, http://links.lww.com/SLA/C719). The first control cohort was cases with the same risks that were performed by non-Lapco delegates. Cases were matched by using propensity scores, derived from a logistic regression model with whether or not the surgeon was a Lapco delegate as the dependent variable and the case mix variables that might have led to case selection (as above) as the independent variables. Using the propensity scores of the cases done by the Lapco delegates, we extracted cases from non-Lapco surgeons on a one-to-one basis, distributed over the four time periods, 2004 - 2006, 2007 - 2009, 2010 
$-2012,2013-2015$. The time periods were chosen to account for the fact that delegates entered training in different times. The second patient cohort was cases performed by the 65 expert Lapco trainers. As the cohort of expert cases was smaller, a tolerance of 0.01 was applied to the one-to-one propensity score-based case match. Furthermore, in order to examine the possibility of the selection bias of Lapco delegates who may be a more motivated cohort and hence have a better improvement over time, we plotted and visually inspected the annual trends of clinical outcomes in Lapco delegates and non-Lapco surgeons before Lapco.

We employed risk-adjusted cumulative sum (RA-CUSUM) analysis to identify changes in the clinical outcomes during Lapco (available in the Supplement, http://links.lww.com/SLA/C719) and to assess predictive validity of the in-training assessment tools. CUSUM analysis enabled the identification of an inflection in the learning curve', which corresponded to a change point in the cumulative values of the dependent variable (clinical outcomes) before versus after the change point. We assessed the significance of change using boot-strapping simulation $(\mathrm{k}=1000)$. The confidence level was set at $95 \%$ so that the observed learning curve (and its change point) was more pronounced than at least $95 \%$ of all the simulated learning curves from the same data, albeit in random orders of the independent variable.

RA-CUSUM was also applied to assess influences of training on post-Lapco performance, by identifying the change points in training metrics, i.e. cut-off values of GAS and CAT scores, training volume and frequency, and their associations with more frequent laparoscopic surgeries post-Lapco. Predictive clinical validity of GAS and CAT scores would be confirmed if the change point in the rate of laparoscopic surgery post-Lapco was near the predetermined competent level of 5 and 3 for GAS and CAT respectively. Regression models were used for risk-adjustment to include the potential confounding factors (age, gender, Charlson comorbidity index and resection type), which were well-recognized predictors of laparoscopy provided in $\mathrm{HES}^{13}$.

Significance level of all the statistical tests was set at 5\%. CUSUM curves were computed using Excel (Excel for Mac 2011, version 14.1.4, Microsoft Corporation). For the remaining statistical analysis, the SPSS software was used (Statistical Package for the Social Sciences software, Version 24, SPSS Chicago (IL), USA).

\section{RESULTS}

One hundred and forty-four Lapco delegates performed 1,782 laparoscopic colorectal training cases under supervision in Lapco. A total of 1,648 Lapco trainer GAS forms and 1,327 delegate GAS forms were completed. The distribution of case volume and sign-off success rate using CAT were shown in eFigure 1 in the Supplement, http://links.lww.com/SLA/C719.

\section{Safety and quality of training during Lapco}

Clinical outcomes during Lapco included 30-day mortality of $0.5 \%$, a conversion rate of $4.9 \%$, reoperation rate of $3.9 \%$ and readmission rate of $3 \%$ while the median length of 
hospital stay was 5 days (interquartile rang 4-7). None of the Lapco proficiency-gain curves for clinical outcomes had apparent change points during Lapco apart from conversion which showed an apparent change point at 12 cases with a confidence level of $96.2 \%$ where conversion rate fell from $5.9 \%$ to $3.0 \%(\mathrm{p}=0 \cdot 01)$. (eFigure 2 in the Supplement, http://links.lww.com/SLA/C719).

Eighty-one Lapco delegates assessed by 49 trainers with an average overall mini-STTAR score of 4.51 (with the maximum score being five). Neither case or patient characteristics or delegate level had an influence on the mini-STTAR score (eTable 2 in the Supplement, http://links.lww.com/SLA/C719). Lapco structure and organization were highly rated by delegates and trainers (available in the Supplement, http://inks.lww.com/SLA/C719).

\section{Clinical outcomes post-Lapco}

The 108 Lapco delegates, with $\geq 5$ training cases, performed 4586 elective colorectal cancer resections pre-Lapco and 5115 post-Lapco. The non-Lapco matched control group of 796 surgeons performed 72930 elective colorectal cancer cases within the same time period. The matched demographics were identical in both groups and there were no significant changes in demographics of the cases performed pre- and post-Lapco (eTable 3 through eTable 6 in the Supplement, http://links.lww.com/SLA/C719). Trend graphs excluded a baseline difference between Lapco delegates and non-Lapco surgeons that may account for the observed difference in outcomes (Figure 1).

The Lapco delegates increased the rate of laparoscopic surgery by $37.8 \%$ (95\% CI, $36.1 \%$ to $39.4 \%$ ), from $12.8 \%$ to $50.6 \%$, that was greater than the non-Lapco surgeons by $20.9 \%(95 \%$ CI, $18.5 \%$ to $23.3 \%$ ). The difference in differences analysis showed that Lapco delegates also had a relative decrease in conversion rate of $-4.8 \%$ (95\% CI, $-9.1 \%$ to $-0.5 \%)$. In laparoscopic cases, Lapco delegates also had a relative reduction in re-intervention rate by $-5.0 \%(95 \% \mathrm{CI}$, $-8.2 \%$ to $-1.7 \%$ ). The overall 30 - and 90 -day mortality of cases performed by Lapco delegates after the program fell respectively by $-1.4 \%(95 \% \mathrm{CI},-0.8 \%$ to $-2.0 \%)$ and by $-1.7 \%(95 \%$ CI, $-1.0 \%$ to $-2.4 \%$ ) compared to cases performed prior to joining Lapco. The majority of this decrease was due to a reduction in mortality of laparoscopic cases (30-day by $-1.8 \%$ (95\% CI, $-0.6 \%$ to $-3.6 \%), 90$-day by $-2.4 \%(95 \% \mathrm{CI},-1.0 \%$ to $-4.4 \%)$. There was a greater reduction in 30 -day mortality rate by $-1.6 \%(95 \% \mathrm{CI},-3.4 \%$ to $-0.2 \%)$ and 90 -day mortality rate by $2.3 \%(95 \% \mathrm{CI},-4.3 \%$ to $-0.4 \%)$ in laparoscopic cases (Table $1 \mathrm{a}$ and $1 \mathrm{~b})$.

Comparing Lapco delegates to the expert trainers found similar results. The difference in differences analysis showed that Lapco delegates had an increased rate of laparoscopic surgery by $33.3 \%$ (95\% CI, $30.7 \%$ to $36.0 \%$ ). In laparoscopic cases, there was a relative reduction in 30 -day mortality by $-1.1 \%(95 \% \mathrm{CI},-2.1 \%$ to $-0.1 \%)$ and in 90 -day mortality by $-1.3 \%$ (95\% CI $-2.7 \%$ to $-0.1 \%$ ) (eTable 7 in the supplement, http://links.lww.com/SLA/C719).

There was a strong relationship between both GAS and CAT scores and the post-Lapco rate of laparoscopic surgery. Delegates with a trainer GAS score of $>4.74$, delegate GAS score $>4.67$ and a CAT score $>3.12$ had a higher rate of laparoscopic surgery post-Lapco (Figure 2 ). Delegates with a higher training volume ( $>15$ cases $)$ and training frequency $(>1.06$ cases 
per month) had higher post-Lapco rates of laparoscopic surgery; 44\% vs 55\% (p<.001) and $43 \%$ vs $55 \%(\mathrm{p}<.001)$ respectively (eFigures $3-4$ in the Supplement, http://links.lww.com/SLA/C719).

\section{DISCUSSION}

The English national training program in laparoscopic colorectal surgery resulted in a significant increase in the rate of use of laparoscopic colorectal cancer surgery and an improvement in clinical outcomes including a decrease in conversion rate and morbidity as well as a reduction in 30- and 90-day and one-year mortality of cases performed by Lapco surgeons after embarking on independent practice. This improvement is unlikely to be explained by non-training factors evolving over time or by a better selection of surgeons entering the Lapco training program. In addition, all clinical outcomes including mortality during Lapco were better than that observed at a national level ${ }^{2}$ with no proficiency-gain curve observed in complications, apart from conversion rate, confirming the clinical safety during training. The clinical outcomes of Lapco provide the highest level of evidence for the impact of an educational intervention (level $4 \mathrm{~b}$ Kirkpatrick model for training assessment) ${ }^{14}$ and surgical innovation (assessment in the IDEAL framework) ${ }^{15}$.

Lapco is a competency-based training program. There was a strong relationship between the GAS and CAT scores and the post-Lapco rate of laparoscopic surgery confirming the predictive clinical validity of Lapco competency assessment tools. Those findings further the evidence by Birkmeyer et al who showed that greater skills on video-based assessment were associated with fewer post-operative complications by specialists in bariatric surgery. ${ }^{16}$ Lapco developed and employed objective tools with a cut-off level for skills assessment during training (GAS) and before embarking on independent practice (CAT) that predicted outcomes in subsequent clinical performance. This predictive clinical validity provides the evidence for the potential of using such tools in training programs.

The quality of training provision is crucial during large-scale training programs. ${ }^{17,18}$ Trainingthe-Trainer courses standardized, benchmarked and improved the quality of training delivery ${ }^{11}$ that was quantitively assessed using mini-STTAR during training cases and qualitatively examined after completion of Lapco.

As a national training programme, Lapco required substantial funding. However, Lapco has been cost-neutral due to the savings in treating fewer complications and the reductions in the length of hospital stay associated with the reduced length of proficiency gain curve. The required resources for a new programme adopting the Lapco model would include the equipment for the new procedure and the administration and trainers' time. Lapco researchers have made competency assessment tools available and they only need minor adaptation to suit a new procedure. Although the Department of Health in England has led the way to fund Lapco, it is the duty of educational bodies and industry introducing new technologies to fund training programs for specialists as gaining competency at the expense of patient safety is no longer acceptable. 
There are limitations to the study. The precision of the HES database is reliant on coding by individual institutions, albeit HES has been shown to be accurate and a reliable data set for comparison of mortality ${ }^{17}$. Unfortunately, the HES database does not include some risk factors such as body mass index, previous surgery and tumor characteristics, which limited risk-adjustment. However, tumor characteristics are unlikely to influence the short-term clinical outcomes studied here. Standardization of outcomes such as conversion is not realistic nationally and is therefore reliant on individual interpretation. Identification of individual surgeons within the HES database was made using a unique anonymized providerspecific code for the specialist surgeon. The procedure may have been performed by a trainee surgeon but captured within the consultant's proficiency-gain curve analysis. However, it is unlikely that the trainee has better technical skills than the supervising consultant and the ultimate responsibility would rest with the consultant. As our study was conducted in an English setting, factors that might be relevant to other healthcare settings, such as consultant movements between hospitals, were not considered. Nevertheless, Lapco program has been adopted internationally, thus lending external utility to the approach. Finally, it may be possible that Lapco had also influenced referral patterns as surgeons with specialized training were more likely to be referred patients suitable for laparoscopic surgery.

In conclusion, Lapco showed that training specialists in emerging technologies at a national level is realizable, safe and improves clinical outcomes including mortality rates.

Competency-based training programs minimize harm to patients while surgeons gain competency. Lapco provides a valid educational platform for national clinical training programs for specialist surgeons in evolving technologies. The Lapco model is currently being utilized in national and international initiatives worldwide in laparoscopic colorectal surgery, trans-anal total mesorectal excision of rectum; laparoscopic hysterectomy and robotic surgery in several European countries, USA and Australia.

\section{AUTHORS CONTRIBUTION}

Conception of program structure: GBH, MGC, RHK.

Development and validation of competency assessment tool and global assessment score: DM, GBH, MN, SW.

Development of STTAR and training assessment at completion of Lapco: SW, GBH, DM, MN, RHK, NKF, MGC.

Development, validation and delivery of Lapco Training-the-Trainer curriculum: MGC, NKF, TC, HM, GBH.

Study design: GBH, HM, DM, MN, MGC.

HES data analysis: HM, PA.

Analysis of the results on competency assessment tool and global assessment score: HM, MN.

Interpretation of results: GBH, HM, MN, DM, MGC, PA. 
Leading national coordination clinical center: MGC.

Leading national academic educational center: GBH.

Leading clinical training: AP, TC, AG, JG, JMR, CS, TR, AA, CMA, JTJ, AH, CC, IL, TA, RWM, NKF, RHK, MGC.

Clinical training, implementing assessment tools in Lapco centers and scoring videos in the sign-off process: AP, TC, AG, JG, JMR, CS, TR, AA, CMA, JTJ, AH, CC, IL, TA, RWM, $\mathrm{NKF}, \mathrm{RHK}, \mathrm{MGC}$ and surgeons in the acknowledgement section.

Drafting the manuscript: GBH, HM, MN.

Editing the manuscript and approval of final version: all authors.

Custodian of study: GBH.

\section{ETHICS}

Ethics approval for using data from the Hospital Episodes Statistics (HES) for research and measuring quality of delivery of healthcare was obtained from the London - South East Ethics Committee (REC ref 15/LO/0824).

\section{ACKNOWLEDGEMENTS}

Cancer Action Team, Department of Health

Prof Sir Mike Richards (CQC Chief Inspector of Hospitals, Retired), Teresa Moss (Director Transforming Cancer Services Team for London, Retired) and Andrew McMeeking (Deputy Director Transforming Cancer Services Team for London).

Trainers

Mr David Watson, Mr Dominic Slade and Mr Arif Khan (Department of colorectal Surgery, The Christie NHS Foundation Trust, Manchester), Andrew Miller (Nottingham University Hospitals NHS Trust), Hugh Gallagher, Mark Kratory (Department of Surgery, Freeman Hospital, Newcastle), Sharmila Gupta (East Suffolk and North Essex NHS Foundation Trust), Robert Longman (University Hospitals Bristol NHS Foundation Trust), Jim Khan (Portsmouth Hospitals NHS Trust), Simon Radley (University Hospitals Birmingham NHS Foundation Trust), John Hartley (Hull and East Yorkshire Hospitals NHS Trust), Dominic Slade, David Watson (Salford Royal NHS Foundation Trust), Mike Parker (Dartford and Gravesham NHS Trust, Retired), John Monson (Digestive Health and Surgery Institute, Orlando Florida)

Plymouth Administration Team

Laura Langsford (University Hospitals Plymouth NHS Trust). 


\section{REFERENCES}

1. Miskovic D, Ni M, Wyles SM, et al. Learning curve and case selection in laparoscopic colorectal surgery: systematic review and international multicenter analysis of 4852 cases. Diseases of the Colon \& Rectum 2012; 55(12):1300-10.

2. Mackenzie H, Markar SR, Askari A, et al. National proficiency-gain curves for minimally invasive gastrointestinal cancer surgery. Br J Surg 2016; 103(1):88-96.

3. Guillou PJ, Quirke P, Thorpe H, et al. Short-term endpoints of conventional versus laparoscopic-assisted surgery in patients with colorectal cancer (MRC CLASICC trial): multicentre, randomised controlled trial. Lancet 2005; 365(9472):1718-26.

4. Group COoSTS. A comparison of laparoscopically assisted and open colectomy for colon cancer. $N$ Engl J Med 2004; 350(20):2050-9.

5. Buunen M, Veldkamp R, Hop WC, et al. Survival after laparoscopic surgery versus open surgery for colon cancer: long-term outcome of a randomised clinical trial. Lancet Oncol 2009; 10(1):44-52.

6. Jayne DG, Thorpe HC, Copeland J, et al. Five-year follow-up of the Medical Research Council CLASICC trial of laparoscopically assisted versus open surgery for colorectal cancer. Br J Surg 2010; 97(11):1638-45.

7. Prakash K, Kamalesh NP, Pramil K, et al. Does case selection and outcome following laparoscopic colorectal resection change after initial learning curve? Analysis of 235 consecutive elective laparoscopic colorectal resections. J Minim Access Surg 2013; 9(3):99-103.

8. Miskovic D, Wyles SM, Carter F, et al. Development, validation and implementation of a monitoring tool for training in laparoscopic colorectal surgery in the English National Training Program. Surg Endosc 2011; 25(4):1136-42.

9. Miskovic D, Ni M, Wyles SM, et al. Is competency assessment at the specialist level achievable? A study for the national training programme in laparoscopic colorectal surgery in England. Ann Surg 2013; 257(3):476-82.

10. Mackenzie H, Ni M, Miskovic D, et al. Clinical validity of consultant technical skills assessment in the English National Training Programme for Laparoscopic Colorectal Surgery. Br J Surg 2015; 102(8):991-7.

11. Mackenzie H, Cuming T, Miskovic D, et al. Design, delivery, and validation of a trainer curriculum for the national laparoscopic colorectal training program in England. Ann Surg 2015; 261(1):149-56.

12. Wyles SM, Miskovic D, Ni Z, et al. Development and implementation of the Structured Training Trainer Assessment Report (STTAR) in the English National Training Programme for laparoscopic colorectal surgery. Surg Endosc 2015.

13. Askari A, Nachiappan S, Currie A, et al. Selection for laparoscopic resection confers a survival benefit in colorectal cancer surgery in England. Surg Endosc 2016; 30(9):3839-47. 


\section{FIGURE LEGENDS}

Figure 1. Trend graphs pre- and post-Lapco period.

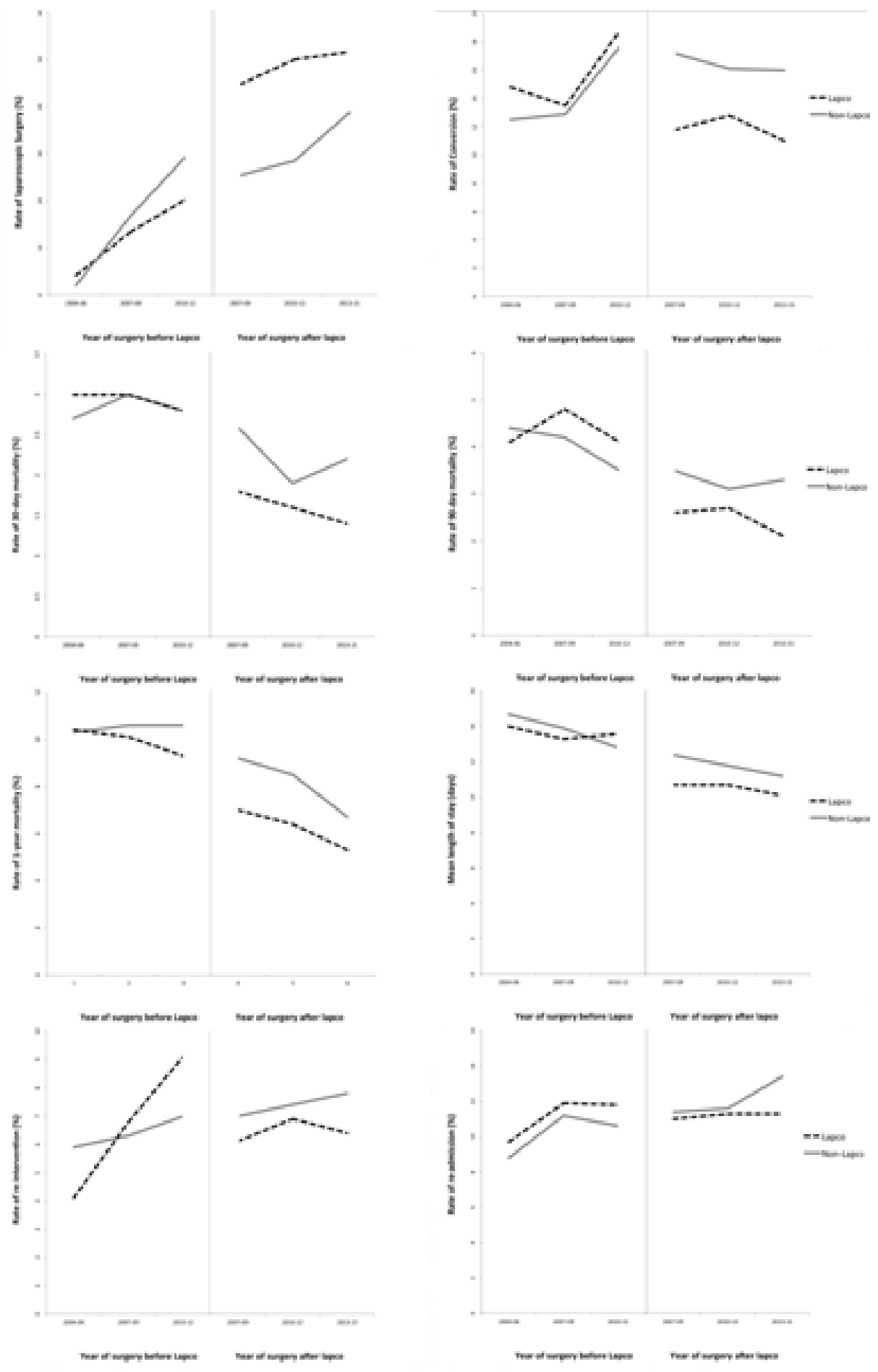

Copyright @ 2020 Wolters Kluwer Health, Inc. Unauthorized reproduction of this article is prohibited. 
Figure 2a. Training progression: Global Assessment Score (GAS) by delegates.

CUSUM curve demonstrates the relationship between GAS scores (x-axis) and the cumulative differences between the actual number of Lapco cases performed by the delegates versus the expected number of cases (y-axis). A change point was demonstrated at $4 \cdot 67$ where laparoscopic rate increased from $37 \%$ to $56 \%$. The pre-determined competency score was 5.

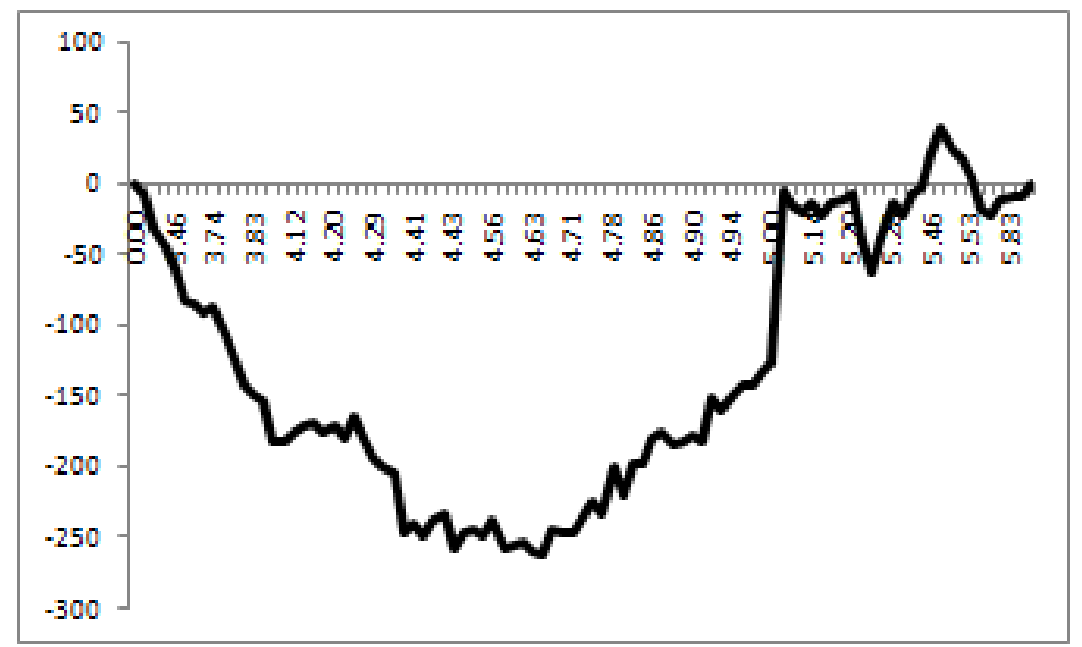

Figure 2b. Training progression: Global Assessment Score (GAS) by trainers.

CUSUM curve demonstrates the relationship between GAS scores ( $\mathrm{x}$-axis) and the cumulative differences between the actual number of Lapco cases performed by the delegates versus the expected number of cases (y-axis). A change point was demonstrated at $4 \cdot 74$ where laparoscopic rate increased from $40 \%$ to $56 \%$. The pre-determined competency score was 5.

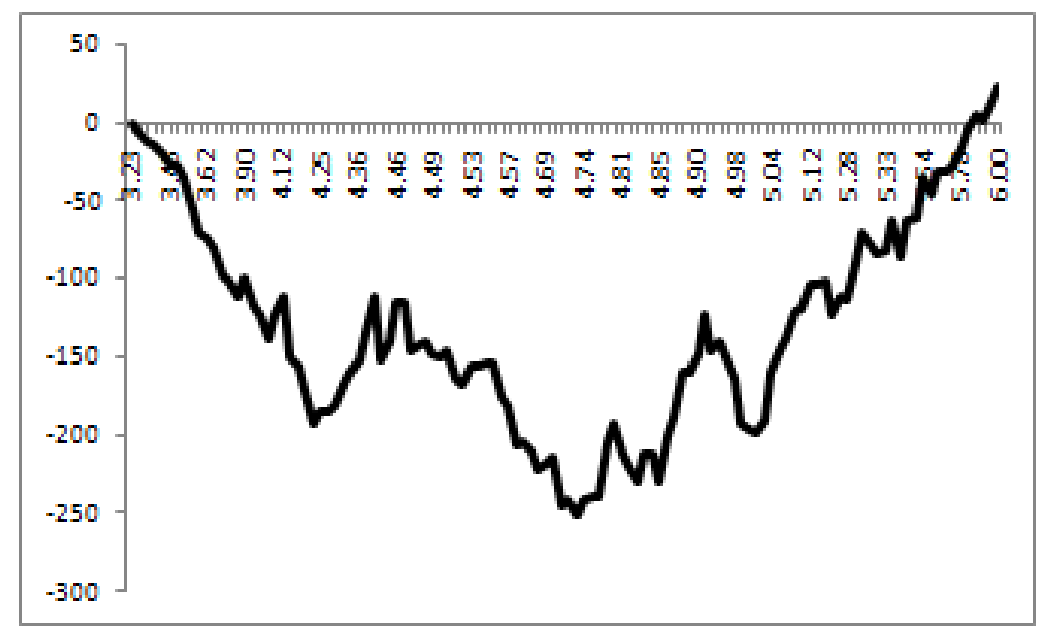


Figure 2c. Sign-off to independent practice: Competency Assessment Tool (CAT).

CUSUM curve demonstrates the relationship between CAT scores (x-axis) and the cumulative differences between the actual number of Lapco cases performed by the delegates versus the expected number of cases (y-axis). A change point was demonstrated at $3 \cdot 12$ where laparoscopic rate increased from $44 \%$ to $66 \%$. The pre-determined competency score was 3.

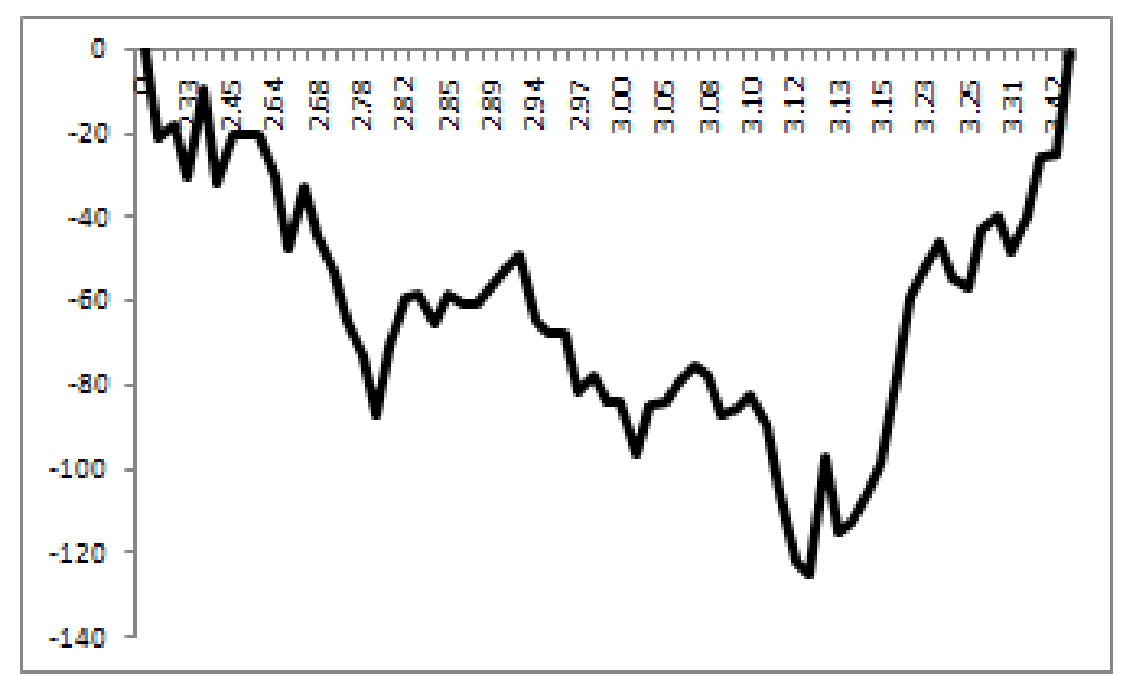


Table 1a. Clinical outcomes of cases by Lapco delegates compared to non-Lapco surgeons in rate of laparoscopic surgery, 30-day, 90-day and 1-year mortality.

\begin{tabular}{|c|c|c|c|c|c|c|c|c|}
\hline \multirow[b]{3}{*}{$\begin{array}{l}\text { Rate of } \\
\text { laparoscopic } \\
\text { surgery }\end{array}$} & & \multicolumn{3}{|c|}{ Lapco delegates } & \multicolumn{3}{|c|}{ Non-Lapco Surgeons } & \multirow{2}{*}{$\begin{array}{l}\text { Difference in } \\
\text { Difference }\end{array}$} \\
\hline & & Pre-Lapco & $\begin{array}{l}\text { Post- } \\
\text { Lapco }\end{array}$ & $\begin{array}{c}\mathrm{p}- \\
\text { value }\end{array}$ & Pre-Lapco & $\begin{array}{l}\text { Post- } \\
\text { Lapco }\end{array}$ & $\begin{array}{c}\mathrm{p}- \\
\text { value }\end{array}$ & \\
\hline & Laparoscopy & $587(12.8)$ & $\begin{array}{l}2588 \\
(50.6)\end{array}$ & $<.001$ & $733(16.0)$ & $\begin{array}{l}1681 \\
(32.9)\end{array}$ & $<.001$ & $\begin{array}{c}20.9(18.5 \text { to } \\
23.3)\end{array}$ \\
\hline Total (\%) & Conversion & $85(14.5)$ & $310(12.0)$ & 0.1 & $101(13.8)$ & $270(16.1)$ & 0.15 & $\begin{array}{c}-4.8(-9.1 \text { to }- \\
0.5)\end{array}$ \\
\hline $\begin{array}{l}\text { 30-Day } \\
\text { Mortality }\end{array}$ & Overall & $\begin{array}{c}135 / 4586 \\
(2.9)\end{array}$ & $\begin{array}{c}71 / 4779 \\
(1.5)\end{array}$ & $<.001$ & $\begin{array}{c}134 / 4586 \\
(2.9)\end{array}$ & $\begin{array}{c}103 / 4929 \\
(2.1)\end{array}$ & 0.009 & $\begin{array}{c}-0.6(-1.5 \text { to } \\
0.2)\end{array}$ \\
\hline \multirow[t]{3}{*}{ Total (\%) } & Laparoscopic & $\begin{array}{c}13 / 502 \\
(2.6)\end{array}$ & $\begin{array}{c}16 / 2122 \\
(0.8)\end{array}$ & $<.001$ & $\begin{array}{c}13 / 632 \\
(2.1)\end{array}$ & $\begin{array}{c}26 / 1335 \\
(1.9)\end{array}$ & 0.87 & $\begin{array}{c}-1.6(-3.4 \text { to }- \\
0.2)\end{array}$ \\
\hline & Converted & $2 / 85(2.4)$ & $\begin{array}{c}4 / 283 \\
(1.4)\end{array}$ & 0.55 & $4 / 101(4.0)$ & $\begin{array}{l}6 / 256 \\
(2.3)\end{array}$ & 0.4 & $\begin{array}{c}0.7(-4.2 \text { to } \\
5.6)\end{array}$ \\
\hline & Open & $\begin{array}{c}120 / 3999 \\
(3.0)\end{array}$ & $\begin{array}{c}51 / 2374 \\
(2.1)\end{array}$ & 0.04 & $\begin{array}{c}117 / 3853 \\
(3.0)\end{array}$ & $\begin{array}{c}71 / 3338 \\
(2.1)\end{array}$ & 0.02 & $\begin{array}{c}0.0(-1.0 \text { to } \\
1.2)\end{array}$ \\
\hline \multirow[t]{4}{*}{$\begin{array}{l}\text { 90-Day } \\
\text { Mortality }\end{array}$} & Overall & $\begin{array}{c}190 / 4586 \\
(4.1)\end{array}$ & $\begin{array}{c}117 / 4779 \\
(2.4)\end{array}$ & $<.001$ & $\begin{array}{c}211 / 4586 \\
(4.6)\end{array}$ & $\begin{array}{c}158 / 4929 \\
(3.2)\end{array}$ & $<.001$ & $\begin{array}{c}-0.3(-1.4 \text { to } \\
0.8)\end{array}$ \\
\hline & Laparoscopic & $\begin{array}{c}18 . / 502 \\
(3.6)\end{array}$ & $\begin{array}{c}25 / 2122 \\
(1.2)\end{array}$ & $<.001$ & $\begin{array}{c}17 / 632 \\
(2.7)\end{array}$ & $\begin{array}{c}35 / 1335 \\
(2.6)\end{array}$ & 0.93 & $\begin{array}{c}-2.3(-4.3 \text { to }- \\
0.4)\end{array}$ \\
\hline & Converted & $2 / 85(2.4)$ & $\begin{array}{c}8 / 283 \\
(2.8)\end{array}$ & 0.81 & $5 / 101(5.0)$ & $\begin{array}{c}11 / 256 \\
(4.3)\end{array}$ & 0.79 & $\begin{array}{c}1.1(-5.1 \text { to } \\
7.4)\end{array}$ \\
\hline & Open & $\begin{array}{c}170 / 3999 \\
(4.3)\end{array}$ & $\begin{array}{c}84 / 2374 \\
(3.5)\end{array}$ & 0.16 & $\begin{array}{c}189 / 3853 \\
(4.9)\end{array}$ & $\begin{array}{c}112 / 3338 \\
(3.4)\end{array}$ & 0.001 & $\begin{array}{c}0.7(-0.5 \text { to } \\
2.2)\end{array}$ \\
\hline 1-year mortality & Overall & $\begin{array}{c}461 / 4586 \\
(10.1)\end{array}$ & $\begin{array}{c}286 / 4779 \\
(6.0)\end{array}$ & $<.001$ & $\begin{array}{c}488 / 4586 \\
(10.6)\end{array}$ & $\begin{array}{c}382 / 4929 \\
(7.8)\end{array}$ & $<.001$ & $\begin{array}{c}-1.3(-2.8 \text { to } \\
0.4)\end{array}$ \\
\hline \multirow[t]{3}{*}{ Total $(\%)$} & Laparoscopic & $\begin{array}{c}44 / 502 \\
(8.8)\end{array}$ & $\begin{array}{c}73 / 2122 \\
(3.4)\end{array}$ & $<.001$ & $\begin{array}{c}52 / 632 \\
(8.2)\end{array}$ & $\begin{array}{c}75 / 1335 \\
(5.6)\end{array}$ & 0.03 & $\begin{array}{c}-2.8(-5.7 \text { to } \\
0.3)\end{array}$ \\
\hline & Converted & $9 / 85(10.6)$ & $\begin{array}{c}21 / 283 \\
(7.4)\end{array}$ & 0.35 & 8/101 (7.9) & $\begin{array}{c}24 / 256 \\
(9.4)\end{array}$ & 0.67 & $\begin{array}{c}-4.7(-14.0 \text { to } \\
4.8)\end{array}$ \\
\hline & Open & $\begin{array}{c}408 / 3999 \\
(10.2)\end{array}$ & $\begin{array}{c}192 / 2374 \\
(8.1)\end{array}$ & 0.005 & $\begin{array}{c}428 / 3853 \\
(11.1)\end{array}$ & $\begin{array}{c}283 / 3338 \\
(8.5)\end{array}$ & $<.001$ & $\begin{array}{c}0.5(-1.5 \text { to } \\
2.5)\end{array}$ \\
\hline
\end{tabular}


Table 1b. Clinical outcomes of cases by Lapco delegates compared to non-Lapco surgeons in re-intervention, $\mathrm{LoS}$, complication and re-admission

\begin{tabular}{|c|c|c|c|c|c|c|c|c|}
\hline \multirow[b]{3}{*}{ Re-intervention rate } & & \multicolumn{3}{|c|}{ Lapco delegates } & \multicolumn{3}{|c|}{ Non-Lapco Surgeons } & \multirow{2}{*}{$\begin{array}{l}\text { Difference in } \\
\text { Difference }\end{array}$} \\
\hline & & $\begin{array}{l}\text { Pre- } \\
\text { Lapco }\end{array}$ & $\begin{array}{l}\text { Post- } \\
\text { Lapco }\end{array}$ & $\begin{array}{c}\mathrm{p}- \\
\text { value }\end{array}$ & $\begin{array}{l}\text { Pre- } \\
\text { Lapco }\end{array}$ & $\begin{array}{l}\text { Post- } \\
\text { Lapco }\end{array}$ & $\begin{array}{c}\mathrm{p}- \\
\text { value }\end{array}$ & \\
\hline & Overall & $\begin{array}{l}306 \\
(6.7)\end{array}$ & $\begin{array}{l}339 \\
(6.6)\end{array}$ & 0.93 & $\begin{array}{l}291 \\
(6.3)\end{array}$ & $\begin{array}{l}385 \\
(7.5)\end{array}$ & 0.02 & $-1.3(-2.6$ to 0.2$)$ \\
\hline \multirow[t]{3}{*}{ Total $(\%)$} & Laparoscopic & $45(9.0)$ & $\begin{array}{c}125 \\
(5.5)\end{array}$ & 0.003 & $34(5.4)$ & $97(6.9)$ & 0.2 & $-5.0(-8.2$ to -1.7$)$ \\
\hline & Converted & $9(10.6)$ & $18(5.8)$ & 0.12 & $8(7.9)$ & $26(9.6)$ & 0.61 & $\begin{array}{c}-6.5(-15.5 \text { to } \\
2.5)\end{array}$ \\
\hline & Open & $\begin{array}{l}252 \\
(6.3)\end{array}$ & $\begin{array}{c}196 \\
(7.8)\end{array}$ & 0.02 & $\begin{array}{l}249 \\
(6.5)\end{array}$ & $\begin{array}{c}262 \\
(7.6)\end{array}$ & 0.05 & $0.4(-1.4$ to 2.0$)$ \\
\hline \multirow[t]{4}{*}{$\begin{array}{l}\text { Length of hospital } \\
\text { stay (days) }\end{array}$} & Overall & $\begin{array}{c}13.4 \\
(15.9)\end{array}$ & $\begin{array}{c}10.4 \\
(12.4)\end{array}$ & $<.001$ & $\begin{array}{c}13.9 \\
(15.7)\end{array}$ & $\begin{array}{c}11.5 \\
(13.6)\end{array}$ & $<.001$ & $-0.6(-1.5$ to 0.2$)$ \\
\hline & Laparoscopic & $\begin{array}{c}10.3 \\
(14.9)\end{array}$ & $7.9(9.2)$ & $<.001$ & $\begin{array}{c}10.4 \\
(14.7)\end{array}$ & $8.2(8.1)$ & $<.001$ & $-0.2(-1.6$ to 1.2$)$ \\
\hline & Converted & $\begin{array}{l}17.9 \\
(27.2)\end{array}$ & $\begin{array}{c}11.4 \\
(11.0)\end{array}$ & 0.05 & $\begin{array}{c}13.3 \\
(14.2)\end{array}$ & $\begin{array}{c}15.0 \\
(20.8)\end{array}$ & 0.74 & $\begin{array}{c}-8.2(-14.0 \text { to }- \\
2.2)\end{array}$ \\
\hline & Open & $\begin{array}{c}13.8 \\
(15.6)\end{array}$ & $\begin{array}{c}12.5 \\
(14.5)\end{array}$ & $<.001$ & $\begin{array}{c}14.5 \\
(15.8)\end{array}$ & $\begin{array}{c}12.6 \\
(14.4)\end{array}$ & $<.001$ & $0.6(-0.4$ to 1.7$)$ \\
\hline \multirow[t]{4}{*}{$\begin{array}{l}\text { Medical } \\
\text { complications rate }\end{array}$} & Overall & $\begin{array}{c}746 \\
(16.3)\end{array}$ & $\begin{array}{c}968 \\
(18.9)\end{array}$ & 0.001 & $\begin{array}{c}747 \\
(16.3)\end{array}$ & $\begin{array}{c}957 \\
(18.7)\end{array}$ & 0.002 & 0.2 (-1.9 to 2.4$)$ \\
\hline & Laparoscopic & $\begin{array}{c}64 \\
(12.7)\end{array}$ & $\begin{array}{c}388 \\
(17.0)\end{array}$ & 0.02 & $\begin{array}{c}80 \\
(12.7)\end{array}$ & $\begin{array}{c}196 \\
(13.9)\end{array}$ & 0.45 & $3.1(-1.8$ to 7.9$)$ \\
\hline & Converted & $\begin{array}{c}10 \\
(11.8)\end{array}$ & $\begin{array}{c}61 \\
(19.7)\end{array}$ & 0.092 & $\begin{array}{c}14 \\
(13.9)\end{array}$ & $\begin{array}{c}55 \\
(20.4)\end{array}$ & 0.15 & $\begin{array}{c}1.4(-11.4 \text { to } \\
14.2)\end{array}$ \\
\hline & Open & $\begin{array}{c}672 \\
(16.8)\end{array}$ & $\begin{array}{c}519 \\
(20.5)\end{array}$ & $<.001$ & $\begin{array}{c}653 \\
(16.9)\end{array}$ & $\begin{array}{c}706 \\
(20.6)\end{array}$ & $<.001$ & $0.0(-2.5$ to 2.8$)$ \\
\hline \multirow{4}{*}{$\begin{array}{l}\text { Readmission } \\
\text { Total (\%) }\end{array}$} & Overall & $\begin{array}{c}529 \\
(11.5)\end{array}$ & $\begin{array}{c}575 \\
(11.2)\end{array}$ & 0.65 & $\begin{array}{c}496 \\
(10.8)\end{array}$ & $\begin{array}{c}633 \\
(12.4)\end{array}$ & 0.02 & $-1.9(-3.7$ to -0.1$)$ \\
\hline & Laparoscopic & $46(9.2)$ & $\begin{array}{c}247 \\
(10.8)\end{array}$ & 0.27 & $60(9.5)$ & $\begin{array}{c}169 \\
(12.0)\end{array}$ & 0.1 & $-0.9(-5.0$ to 3.4$)$ \\
\hline & Converted & $\begin{array}{c}12 \\
(14.1)\end{array}$ & $\begin{array}{c}38 \\
(12.3)\end{array}$ & 0.65 & $\begin{array}{c}11 \\
(10.9)\end{array}$ & $\begin{array}{c}33 \\
(12.2)\end{array}$ & 0.72 & $\begin{array}{c}-3.1(-14.1 \text { to } \\
7.7)\end{array}$ \\
\hline & Open & $\begin{array}{c}471 \\
(11.8)\end{array}$ & $\begin{array}{c}290 \\
(11.5)\end{array}$ & 0.71 & $\begin{array}{c}425 \\
(11.0)\end{array}$ & $\begin{array}{c}431 \\
(12.6)\end{array}$ & 0.04 & $-1.9(-4.0$ to 0.4$)$ \\
\hline
\end{tabular}

